\title{
Tesis doctorales presentadas en España y Portugal en 2015 en el ámbito de la SIBB
}

En esta sección de la revista se listan las Tesis Doctorales presentadas en España y Portugal en el año 2015 y recogidas en la base de datos DART.

DART-Europe es una asociación de bibliotecas de investigación y de consorcios bibliotecarios que trabajan conjuntamente para la mejora del acceso global a las tesis doctorales europeas. DART-Europe facilita a los investigadores un único portal europeo para el acceso a tesis electrónicas (http://www.dart-europe.eu/). DART-Europe está apoyado por LIBER (Ligue des Bibliothèques Européennes de Recherche) y es el Grupo Europeo de Trabajo de la Networked Digital Library of Theses and Dissertations (NDLTD)

58 Área de Biomecánica y Medicina del Deporte

60 Área de Cirugía Ortopédica y Traumatología

65 Área de biomateriales 


\title{
Deporte y flexibilidad : rendimiento deportivo sin riesgo de lesión
}

\author{
Autor \\ CEJUDO PALOMO, ANTONIO \\ Directores \\ AYALA RODRÍGUEZ, FRANCISCO; SAINZ DE BARANDA ANDÚJAR, PILAR; \\ SANTONJA MEDINA, FERNANDO \\ Universidad de Murcia \\ Fecha de lectura: 18 diciembre 2015
}

Presentar una propuesta específica para la valoración del rango de movimiento (ROM) de las articulaciones de la cadera, rodilla y tobillo "Protocolo ROM-SPORT", en base a criterios de validez y fiabilidad, sencillez del procedimiento exploratorio y austeridad en los recursos humanos y materiales.Analizar la precisión "Fiabilidad de la medida" de las pruebas de valoración del protocolo ROM-SPORT.Determinar el perfil de flexibilidad de la extremidad inferior en diferentes deportes mediante el protocolo ROM-SPORT

Palabras clave: Deportistas-Rendimiento; Lesiones deportivas-Prevención

Enlace de acceso: http://hdl.handle.net/10803/359385

\section{Monitorización y estudio de las relaciones entre la carga de entrenamiento, la producción de fuerza, la fatiga y el ren- dimiento en corredores de alto nivel}

\author{
Autor \\ BALSALOBRE-FERNÁNDEZ, CARLOS \\ Directores \\ CAMPO VECINO, JUAN DEL; TEJERO GONZÁLEZ, CARLOS MARÍA \\ Universidad dAutónoma de Madrid \\ Fecha de lectura: 30 abril 2015
}

RESUMEN NO DISPONIBLE

Enlace de acceso: http://hdl.handle.net/10486/666390 


\title{
La motivación en el Baloncesto profesional. Relación con los parámetros fisiológicos y físicos
}

\author{
Autor \\ LISBONA ROLDÁN, ÓSCAR \\ Directores \\ CASTILLO RODRÍGUEZ, ALFONSO; MONTIEL GÁMEZ, PEDRO \\ Universidad de Málaga \\ Fecha de lectura: 2015
}

\begin{abstract}
La Actividad Física protege nuestra salud (Díaz, 2009) y evita hábitos no recomendados (Pérez et al., 2010). La investigación en las Ciencias de la Actividad Física y el Deporte ha sido importante en el pasado (López, 2000), pero también lo es en el presente, tanto en el deporte extraescolar (Luengo, C., 2007) como en el deporte profesional (Lozano, 2004), donde se busca continuamente mejorar el rendimiento individual y colectivo. La motivación es un aspecto cognitivo que puede contribuir en el mismo. El desarrollo teórico de esta Tesis Doctoral busca clarificar las variables de la misma en cuatro capítulos: 1. Condición Física y rendimiento de los deportistas, 2. Desarrollo teórico de la Motivación, 3. La Composición Corporal de los deportistas de élite, y 4. Deportes Colectivos. Se han encontrado evidencias científicas de que algunos tipos de Motivación Intrínseca, en especial, la Motivación Intrínseca para conseguir, experimenta un aumento en todos los deportes en la Fase Middle, la Motivación Intrínseca para conocer en la Fase PRE y POST, y la Amotivación o pérdida de motivación con la Fase Post un aumento en determinadas fases de la temporada. La Motivación parece estar relacionada con algunos parámetros corporales y con la condición física de los deportistas. No así con la antigüedad de los mismos. Se ha comprobado que el estado motivacional varía a lo largo de la temporada, y la relación entre algunos parámetros corporales y la condición física, donde se considera que a mayor grasa corporal, menos VO2 máx. En la realización de la Tesis se han utilizado más de 270 referencias bibliográficas, la mayoría de ellas, actualizadas. Se han consultado diferentes bases de datos y revistas científicas de diferente impacto, así como la visita a las páginas webs actualizadas de diferentes federaciones deportivas.
\end{abstract}

Palabras clave: Ejercicio físico; Aspectos fisiológicos

Enlace de acceso: http://hdl.handle.net/10630/9757 


\title{
Lumbalgia, Ortesis y Calidad de vida
}

\author{
Autor \\ GARCÍA PÉREZ-TEIJÓN, CARLOS \\ Directores
CUADRADO CENZUAL, MARÍA ÁNGELES; MARTÍN FERRERO, \\ MIGUEL ÁNGEL; PEDRO MORO, JOSÉ ANTONIO DE \\ Universidad de Salamanca \\ Fecha de lectura: 2015
}

Los sistemas estabilizadores pasivos de la columna son los ligamentos y el disco, y los activos los músculos. Entre los ligamentos de la columna uno de los más interesantes, en términos biomecánicos, es el ligamento amarillo. Su gran cantidad de fibras elásticas le da su color característico y le permite actuar como un resorte almacenando energía durante la flexión y posteriormente ayudando a los músculos durante la extensión. Su capacidad elástica le impide protruir dentro del canal en extensión cuando está en máxima relajación. (16) Otro ligamento importante es el supraespinoso. Por ser el que está más alejado del centro de movimiento vertebral, su brazo de palanca es el más largo y el que puede proporcionar una mayor resistencia a la tracción. La musculatura no solamente es un elemento que da movilidad sino una gran estabilidad a la columna. Un sofisticado elemento de estabilización es la "cámara hidroaérea" formada por el tórax y el abdomen. Cuando se realiza un esfuerzo importante, la glotis y los esfinteres del periné se cierran automáticamente, creando una presión positiva abdominal. La tensión de la musculatura abdominal comprime la cámara hidroaérea, haciendo que la columna dorsolumbar sea una estructura mucho más rígida. La aponeurosis abdominal y la fascia dorsolumbar están unidas y esta última se tensa por la contracción del dorsal ancho que se inserta en la parte proximal del húmero. La resistencia de la columna dorsolumbar está marcada por la calidad de la musculatura abdominal $\mathrm{Al}$ aproximar los brazos al tronco, se tensan las estructuras lumbares en una conexión entre las extremidades superiores y la parte baja de la columna La aplicación de los principios biomecánicos para el manejo de las fracturas de huesos largos también tiene valor para el manejo de lesiones traumáticas inestables de la columna torácica y lumbar. Realmente el principio no funciona sobre cada cuerpo vertebral en sí, sino más bien, toma a toda la columna como una construcción lineal ósea, asemejándola a un hueso largo. Los principios biomecánicos más usados para la columna tóracolumbar son el principio biomecánico del sostén; del tirante; la combinación de los dos anteriores y el principio biomecánico de la protección. (17) Las curvas fisiológicas que presenta el raquis en el plano sagital permiten el desarrollo armónico de sus funciones. Cuando se produce una fractura a nivel vertebral con deformidad y alteración de dicho perfil, se provoca la alteración de dichas funciones. Las vértebras superiores e inferiores, a la vértebra lesionada, deberán de adaptarse a la nueva situación, intentando compensar esa desviación; esto supondrá una sobrecarga para una serie de elementos que tendrán que cumplir una misión biomecánica para la cual no estaban preparados.

Palabras clave: Lumbalgia; Calidad de vida

Enlace de acceso: http://hdl.handle.net/10366/129404 


\title{
Resultados del tratamiento quirúrgico del Hallux Valgus. Análisis de su influencia sobre la calidad de vida de los pacientes
}

\author{
Autor \\ FERNÁNDEZ HERNÁNDEZ, ÓSCAR \\ Directores \\ RAMOS PASCUA, LUIS RAFAEL; SÁNCHEZ LÁZARO, JAIME; \\ TORANZO MARTÍNEZ, DANIEL \\ Universidad de Salamanca \\ Fecha de lectura: 2015
}

\begin{abstract}
Las deformidades del primer radio del pie están entre las más comunes del pie y, entre ellas, la más común es el hallux abductus valgus. Se define como una deformidad de la primera articulación metatarsofalángica (MF1) con abducción y pronación del dedo gordo del pie, combinado con una prominencia medial de la cabeza metatarsal y una desviación medial del primer metatarsiano (M1). El procedimiento diagnóstico más común es la medición radiológica de los ángulos del hallux valgus (AHV) e intermetatarsal (AIM).El primer metatarsiano es vulnerable a fuerzas extrínsecas debido a la ausencia de inserciones musculares en su cabeza. Las únicas estructuras mediales son la cápsula, el ligamento sesamoideo medial y el ligamento colateral medial, y su fallo es la lesión precoz y esencial de la deformidad. Una vez que M1 comienza a varizarse, los tendones y músculos, estabilizadores en condiciones normales, cambian sus vectores de tracción y se transforman en fuerzas deformantes. Progresivamente, las partes blandas MF laterales se contracturan y las mediales se debilitan. La prevalencia varía en la literatura entre el 7,8-15,4\% en jóvenes, el 23-36,3\% en adultos, y 35,7-46\% en ancianos, presentando una relación directa con la edad, habiéndose encontrado prevalencias del HV incluso del 64,7\%. Aunque el tratamiento del HV es inicialmente conservador, con medidas de protección de las partes blandas, separadores, correctores nocturnos o diurnos, tratamiento rehabilitador y ortesis, plantillas, hielo y antiinflamatorios en una gran parte de las ocasiones el tratamiento acabará siendo quirúrgico. Este estudio pretende hacer una revisión exhaustiva de la sensación subjetiva de mejora en la calidad de vida del paciente operado de hallux valgus, y relacionar dicha mejora con múltiples variables tales como la mejora en la deformidad angular del hallux o la técnica quirúrgica utilizada. El estudio se completa con el análisis de las características epidemiológicas y clínicas de la enfermedad en nuestro área de salud, en un marco demográfico particularmente envejecido: el oeste de la Comunidad Autónoma de Castilla y León.
\end{abstract}

Palabras clave: Cirugía ortopédica; Cirugía ósea

Enlace de acceso: http://hdl.handle.net/10366/127359 


\title{
Consecuencias de la antiagregación plaquetaria y anticoa- gulación en pacientes con fractura de caderas
}

\author{
Autor \\ LÓPEZ ALONSO, SAMUEL \\ Director \\ BLÁZQUEZ ARROY, JUAN LUIS \\ Universidad de Salamanca \\ Fecha de lectura: 2015
}

\begin{abstract}
La fractura de cadera es la causa más común de hospitalización en los servicios de urgencia ortopédicos. Esta patología acarrea problemas que van más allá del daño ortopédico, ocasionando repercusión en áreas tales como geriatría, psiquiatría, trabajo social, terapia ocupacional, rehabilitación y en la economía de la atención sanitaria. El siguiente trabajo de tesis se realizó para conocer la recuperación funcional de los pacientes mayores de 65 años intervenidos de fractura de cadera, a los 3 y 6 meses del alta hospitalaria. Se consideraron cuatro grupos de pacientes: pacientes con tratamiento antiagregante plaquetario, pacientes con tratamiento anticuagulante (acenocumarol), pacientes con ambos tratamientos y pacientes sin tratamiento antiagregante ni anticoagulante (como grupo control). Los objetivos planteados fueron determinar la recuperación funcional en los distintos grupos observados(índice de Barthel 14, índice de Lawton, índice de Katz y CRF). Así mismo identificar la morbilidad (índice de Charlson) y mortalidad e institucionalización asociadas al proceso comparando los diferentes grupos estudiados, e identificar variables relacionadas con la recuperación funcional posterior a dicha fractura de cadera, en un período de tiempo señalado.
\end{abstract}

Palabras clave: Cirugía; Traumatología

Enlace de acceso: $h t t p: / / h d l . h a n d l e . n e t / 10366 / 128365$ 


\title{
Estudio de la influencia del recambio articular en la esfera psicoemocional
}

\author{
Autor \\ NAVARRO SANCHIS, JOSÉ ANTONIO \\ Director \\ CÁCERES I PALOU, ENRIC \\ Universidad Autònoma de Barcelona \\ Fecha de lectura: 21 diciembre 2015
}

\begin{abstract}
Hoy en día se considera el deterioro del aparato locomotor como el segundo problema más importante a la hora de causar problemas de dependencia en los ancianos. La artrosis es una de las causas fundamentales que puede impactar negativamente en ello. Es importante identificar factores relacionados con el grado de satisfacción de los pacientes tras someterse a una intervención de recambio articular. La presencia o no de distrés psicológico, ansiedad y depresión ha sido poco estudiada entre dichos pacientes y menos aún el propio impacto de una intervención de tamaña envergadura sobre dichos factores. Objetivos: Los objetivos del presente trabajo son: a / establecer si el cuestionario HADS es un instrumento de cribaje válido para este perfil de pacientes comparándolo con el SCL-90-R y el SF-36; b / analizar los factores sociodemográficos de género y edad en los pacientes a nivel tanto pre como postquirúrgico; c / estimar la prevalencia de los factores psicológicos (depresión y ansiedad) y los factores sociodemográficos para averiguar si existe relación entre ellos; d / establecer las diferencias entre los factores psicológicos (depresión y ansiedad) a nivel pre y postquirúrgico si es que las hay. Material y métodos: se incluyeron pacientes del Hospital de Traumatología del Hospital Universitario Vall d' Hebron pendientes de intervención de recambio articular diagnosticados con artrosis. Se realizaron dos visitas a dichos pacientes a lo largo del estudio. En ambas visitas debían rellenar un cuaderno de recogida de datos que incluía las variables sociodemográficas consideradas así como los cuestionarios autoaplicados HADS, SCL-90-R y SF-36. Se llevó a cabo un estudio de tipo descriptivo prospectivo (longitudinal) para verificar los objetivos marcados. Resultados: se incluyeron un total de 72 pacientes. Un $42 \%$ varones y un $58 \%$ mujeres. Edad media de 67.5 años. La ansiedad decrece un 26\% entre el pre y el posttest con el SCL-90-R y un $18 \%$ con el HADS. La salud mental mejora un 6\% con el SF-36. No se observaron diferencias significativas para la depresión. Conclusiones: Se comprobó que el HADS puede ser un instrumento válido para este perfil de pacientes sin que se evidenciaran diferencias significativas de género. Se comprobó que según nuestros datos independientemente de otras variables la propia intervención quirúrgica del recambio articular significa una mejoría de los niveles de distrés psicológico (ansiedad y depresión) mostrados por los pacientes.
\end{abstract}

Palabras clave: Prótesis total rodilla; Ansiedad-depresión

Enlace de acceso: http://hdl.handle.net/10803/378366 


\title{
Fracturas tóracolumbares: Valor pronóstico de la evalua- ción por imagen en la calidad de vida del paciente
}

\author{
Autor \\ GARCÍA DE LAS HERAS, BEATRIZ \\ Director \\ GARCÍA DE LUCAS, FERNANDO; PEDRO MORO, JOSÉ ANTONIO DE \\ Universidad de Salamanca \\ Fecha de lectura: 21 diciembre 2015
}

\begin{abstract}
Se han estudiado 65 pacientes con fracturas tóracolumbares. El propósito es conocer si los parámetros de capacitación (resultado clínico y resultado laboral), y los indicadores de calidad de vida y percepción de salud (SF-36 como cuestionario general y Roland-Morris como cuestionario específico) se ven afectados o no por los valores del ángulo de cifosis y del porcentaje de acuñamiento y por la lesión o no del complejo ligamentario posterior, previamente valorados mediante la radiología simple y la resonancia magnética. Los pacientes se agruparon considerando un tratamiento quirúrgico o conservador. Al comparar el ángulo de cifosis, solamente apareció una diferencia significativa en la dimensión vitalidad del SF-36 del grupo quirúrgico, apreciándose un menor valor cuanto mayor es el ángulo de cifosis. No se han encontrado diferencias estadísticamente significativas en ninguno de los dos grupos entre el porcentaje de acuñamiento y los diferentes indicadores y parámetros. Únicamente en el grupo conservador se aprecian resultados estadísticamente significativos entre la lesión del complejo ligamentario posterior y el Roland-Morris, el resultado clínico y laboral y en las dimensiones función física, salud general y vitalidad del SF-36. Comparando los resultados entre ambos grupos, no se han encontrado diferencias significativas en los resultados del Roland-Morris, del SF-36 ni en el ángulo de cifosis. Sí aparecen diferencias en el porcentaje de acuñamiento y en los resultados clínico y laboral. Además se demuestra la necesidad de realizar una resonancia magnética a todas las fracturas tóracolumbares, para evaluar la lesión del complejo ligamentario posterior, que indicaría la existencia de una lesión inestable.
\end{abstract}

Palabras clave: Columna vertebral; Fracturas

Enlace de acceso: http://hdl.handle.net/10366/128849 


\title{
E-glass fiber reinforced composite as an oral implant abutment material. In vitro bacterial adhesion assay and biomechanical tests
}

\author{
Autor \\ ETXEBERRIA URRA, MARINA \\ Directores \\ HENAR, TOMÁS J.; VIÑAS, MIQUEL \\ Universitat de Barcelona \\ Fecha de lectura: 27 juliol 2015
}

\begin{abstract}
Los materiales compuestos de resina reforzados con fibras de vidrio E (FRC) están aumentando su uso en aplicaciones dentales y ortopédicas como materiales de soporte de carga. Esto es debido a que exhiben una mejor adaptación biomecánica con los tejidos vivos en comparación con los materiales tradicionales, así como por sus propiedades biocompatibles. Recientemente, se ha observado que mejora la formación del tejido gingival peri-implantario. Además, pilares de FRC reforzados unidireccionalmente han soportado satisfactoriamente 5 años de fatiga oral simulada. Estos estudios hacen que los FRC sean materiales prometedores para pilares de prótesis sobre implantes. Sin embargo, hay una falta de estudios que comparen la adhesión bacteriana de FRC a los materiales actuales para prótesis sobre implantes. Además, el efecto de la diferente orientación de las fibras en la capacidad de carga de los FRC como pilar implantario está aún por determinar. Por lo tanto, este estudio tuvo como objetivo evaluar los aspectos bacterianos y mecánicos de los FRC en con el fin de investigar un nuevo material alternativo libre de metal como pilar para prótesis sobre implante. La caracterización de la rugosidad superficial se realizó mediante microscopía de fuerza atómica e interferometría de luz blanca, y la humectabilidad se determinó utilizando el método de la gota sésil. Se analizaron los parámetros de superficie obtenidos en función de su eficacia en discriminar materiales y se propuso un conjunto de parámetros con el mayor poder discriminatorio (Estudio I). Posteriormente se cuantificó y analizó la adhesión bacteriana de Escherichia coli y Staphylococcus aureus (Estudio II). Por último, se evaluaron las propiedades mecánicas mediante ensayos de flexión de tres puntos y la capacidad de carga estática siguiendo las normas ISO 10477 e ISO 14801 respectivamente (Estudio III). Los resultados de la caracterización de superficie mostraron que los FRC presentan superficies rugosas con características hidrofóbicas. Esta rugosidad aumentó la adhesión bacteriana temprana aunque si nos atenemos al biofilm maduro no se observaron diferencias. Los parámetros Sa, Sku y Smid en la nanoescala, Sa y Sz en la microescala y un ángulo de contacto resultaron ser los más eficaces en la discriminación de biomateriales. Las barras reforzadas bidireccionalmente mostraron una mayor capacidad de fractura en comparación con las unidireccionales. Los pilares de FRC reforzados bidireccionalmente mostraron estadísticamente una mayor capacidad de carga en comparación con pilares reforzados unidireccionalmente. Por lo tanto, debido a su similar respuesta bacteriana con los actuales materiales así como de las adecuadas propiedades mecánicas de los pilares de FRC reforzados bidireccionalmente, se puede concluir que los FRC son materiales alternativos prometedores para su aplicación en prótesis sobre implante.
\end{abstract}

Palabras clave: Materiales dentales; Implantes dentales Enlace de acceso: http://hdl.handle.net/10803/313235 


\title{
Functional copolyesters from castor and sunflower oils, Poly(l-lactide) and poly( $\varepsilon$-caprolactone) using thiol-click chemistry
}

\author{
Autor \\ BEYAZKILIC, ZEYNEP \\ Directores \\ CÁDIZ DELEITO, VIRGINIA; GALIÀ I CLUA, MARINA \\ Universitat Rovira i Virgili \\ Fecha de lectura: 25 marzo 2015
}

\begin{abstract}
El gran desarrollo que están experimentando actualmente los biopolímeros se debe fundamentalmente a los altos precios y disminución de las reservas de petroleo junto con la preocupacion que existe hoy en dia en materia de sostenibilidad ambiental. Por otra parte, además de sus beneficios medioambientales, se puede aprovechar la química "click" para una transformación eficiente de estos materiales. Entre los polímeros de origen renovable los poliésteres alifáticos están entre los más estudiados por ser considerados muy adecuados para aplicaciones como biomateriales debido a su biocompatibilidad y biodegradabilidad. En esta tesis, se han preparado poliésteres renovables combinando la utilización de aceites vegetales (ricino y girasol) y química "click". En particular, se han usado reacciones de acoplamiento tiol-eno y tiol-ino con los ácidos 10-undecenoico y 10-undecinoico, para obtener monómeros de condensación que contienen funcionalidades tioéter y sulfuro de vinilo respectivamente. La adición tio-Michael se aplicó a un derivado del aceite de girasol, el oleato de metilo que contiene un grupo funcional enona, para obtener un monómero hidroxiéster con grupos cetona, capaz de experimentar policondensación. Además, se han sintetizado copoliésteres al azar y en bloque a partir de estos monómeros y ácido poliláctico y policaprolactona para obtener materiales cuyas propiedades les convierten en una alternativa a estos poliésteres convencionales. Por último la modificación de estos materiales permite acceder a una gran variedad de poliésteres funcionalizados.
\end{abstract}

Palabras clave: Poliésteres; química "click"; aceites vegetales

Enlace de acceso: http://hdl.handle.net/10803/319694 


\title{
Glycosynthase Technology for Enzymatic Synthesis of Functionalized Artificial Polysaccharides as New Biomaterials
}

\author{
Autor \\ CODERA PASTOR, MARIA VICTORIA \\ Directores \\ FAIJES SIMONA, MAGDA; PLANAS SAUTER, ANTONI \\ Universidad Ramon Llull \\ Fecha de lectura: 15 juliol 2015
}

\begin{abstract}
La tecnología glicosintasa se ha convertido en una herramienta importante para la síntesis de oligosacáridos, polisacáridos y glicoconjugados. Las glicosintasas son glicosidasas mutadas desprovistas de actividad hidroítica pero capaces de catalizar eficientemente la formación de enlaces glicosídicos con rendimientos elevados utilizando un dador glicosídico activado. Además, el dador activo y su producto de transglicosidación pueden actuar como aceptores dando lugar a la autocondensación del dador o a la elongación del producto de transglicosidación, produciendo polisacáridos. En el presente trabajo se pretenden sintetizar nuevos polisacáridos artificiales funcionalizados con estructuras definidas mediante el uso de la tecnología glicosintasa. Por un lado, se ha intentado aumentar la masa molecular de los polisacáridos utilizando un módulo de unión de carbohidratos (CBM). Este módulo podría mejorar la solubilidad de los nuevos polímeros a medida que se van sintetizando durante la reacción de polimerización. El efecto en el grado de polimerización ha sido estudiado tanto para el mutante glicosintasa en presencia de CBM como para la proteína de fusión glicosintasa-CBM. Por otro lado, se han sintetizado polisacáridos artificiales funcionalizados a partir de dadores disacarídicos activados donde la funcionalización deseada ha sido introducida previamente en la posición C-6'. Estos dadores funcionalizados actúan como sustrato para el mutante glicosintasa que catalizará la reacción de autocondensación. El grupo azido fue escogido por ser un grupo funcional adecuado dada su versatilidad y tamaño, suficientemente pequeño como para ser aceptado por el enzima. Los dadores fluoruro de 6-azidolaminaribiosa y fluoruro de 6-azidocelobiosa han sido sintetizados y evaluados como sustratos para las reacciones glicosintasa con el mutante E134S de la 1,3-1,4- $\beta$-glucanasa de Bacillus licheniformis y el mutante E197A de la celulasa de Humicola insolens, respectivamente. Se han sintetizado 6-azido y 6-amino-6-deoxicelulosas artificiales con una secuencia de funcionalización alternada. De forma opuesta a la modificación química de celulosas donde la secuencia de sustitución es intrínsicamente aleatoria, la polimerización catalizada por glicosintasas de dadores glicosídicos modificados apropiadamente, permite acceder a nuevas celulosas funcionalizadas con secuencias de sustitución definidas y regulares.
\end{abstract}

Palabras clave: Polysaccharides; Glycosynthases; Enzymes; Functionalizations; Synthesis; Carbohydrates; 1,3-1,4-b-glucans; Cellulose; CBM; Regular pattern

Enlace de acceso: http://hdl.handle.net/10803/300592 


\title{
Interacciones de células del linaje osteoblástico con bioma- teriales: influencia en las comunicaciones celulares mediadas por factores solubles
}

\author{
Autor \\ CRESPO GARCÍA, LARA \\ Director \\ VILABOA DÍAZ, NURIA E. \\ Universidad Autónoma de Madrid \\ Fecha de lectura: 20 febrero 2015
}

\begin{abstract}
La aleación Ti6Al4V se utiliza en la fabricación de implantes osteoarticulares debido a sus excelentes propiedades mecánicas, baja toxicidad y buena resistencia a la corrosión. La resistencia a la corrosión se debe a la formación espontánea de una capa de óxido en su superficie, cuya estabilidad se puede alterar en contacto con el medio fisiológico. Con el fin de mejorar la estabilidad de esta capa superficial, en este trabajo se ha sometido la aleación Ti6A14V a tratamientos mediante percusión con láser ("Laser Peening", LP) empleando dos densidades de pulsos de láser, $421 \mathrm{pulsos} / \mathrm{cm} 2$ o $2.524 \mathrm{pulsos} / \mathrm{cm} 2$. La capa superficial de las aleaciones tratadas mediante LP, con rugosidad en el rango submicrométrico, contiene TiO metaestable, además de Ti2O3 e hidróxido de aluminio en su zona más externa. En función de la densidad de pulsos empleada, el tratamiento genera rutilo en dicha capa superficial. Tanto las células madre mesenquimales como los osteoblastos humanos se adhieren a las aleaciones tratadas de forma similar que a la aleación sin tratar. Sin embargo, el proceso de adhesión no ocurre a través de la formación de adhesiones focales que contienen paxilina o FAK fosforilada en la tirosina 397. Ambos tipos celulares proliferan y forman matriz extracelular sobre las aleaciones tratadas de forma similar que sobre la aleación sin tratar. Las aleaciones tratadas favorecen tanto la maduración osteogénica de células madre mesenquimales como la formación de una matriz mineralizada por parte de osteoblastos. En este trabajo también se ha evaluado la influencia de biomateriales con diferentes características químicas y topográficas, tales como poliéster liso, poliestireno poroso, aleación de Ti6Al4V lisa o porosa e hidrogeles de fibrina, sobre el comportamiento de células madre mesenquimales humanas. Asimismo, hemos estudiado la influencia de estos biomateriales en la relación paracrina que establecen las células madre mesenquimales con células osteoblásticas, células madre mesenquimales o células endoteliales humanas. Se observó que las características de los materiales juegan un papel relevante en el control que las células madre mesenquimales ejercen sobre la viabilidad y actividad de los osteoblastos, condicionando tanto la producción de proteínas relacionadas con la organización de la matriz ósea por parte de éstos como la producción de factores implicados en el proceso de remodelado óseo. Además, también regulan el control que las células madre mesenquimales ejercen sobre la supervivencia, capacidad de migración y formación de estructuras tubulares de células endoteliales. Observamos asimismo que el sustrato sobre el que se cultivan las células madre modula las relaciones que establecen con poblaciones del mismo tipo celular con las que no establecen contacto directo, influyendo en su viabilidad. Finalmente, el estudio reveló que las características de los materiales en los que se siembran las células madre mesenquimales modula su respuesta a factores solubles secretados por osteoblastos, células madre mesenquimales y células endoteliales.
\end{abstract}

Palabras clave: Células óseas; Material biomédico

Enlace de acceso: http://hdl.handle.net/10486/664996 


\title{
Ionic copolyesters and their nanocomposites: synthesis, characterization and properties
}

\author{
Autor \\ BAUTISTA BETANCUR; MAYKA IRINA \\ Directores \\ MARTÍNEZ DE ILARDUYA, ANTXON; MUÑOZ GUERRA, SEBASTIÁN \\ Universitat Politécnica de Catalunya \\ Fecha de lectura: 21 setiembre 2015
}

\begin{abstract}
Un polímero que contiene pequeñas proporciones de grupos iónicos, ya sea a lo largo de la cadena principal como en los grupos laterales, es definido como ionómero. Según lo propuesto originalmente por Eisenberg, la interacción entre los grupos iónicos conduce a la formación de multipletes que contienen un grupo reducido de pares iónicos, y también a la formación de clusters, los cuales constituyen una segunda fase compuesta de muchos multipletes, así como de porciones de cadena hidrocarbonada. Estas estructuras iónicas han demostrado actuar como enlaces electrostáticos fuertes entrecruzados, los cuales producen modificacion en las propiedades físicas tales como una mejora de las propiedades mecánicas y un incremento en la viscosidad en fundido, entre otras. Tanto los poliésteres aromáticos como los alifáticos son materiales poliméricos usados ampliamente en la actualidad. Sus aplicaciones más conocidas van desde el campo textil hasta el envasado de alimentos y líquidos como el agua o bebidas carbónicas. La mayoría de los polímeros sintéticos biodegradables son poliésteres alifáticos. Estos poliésteres suelen ser biocompatibles y no tóxicos y juegan un papel clave en aplicaciones médicas debido a su síntesis versátil capaz de proporcionar propiedades a medida. Actualmente se vienen empleando como biomateriales en suturas quirúrgicas, implantes óseos porosos, tornillos y placas de refuerzo, así como portadores de fármacos de liberación controlada. Esta tesis está enfocada en la modificación química de poliésteres aromáticos y alifáticos mediante la incorporación de diferentes grupos iónicos y con diversas concentraciones. Se han sintetizado ionómeros en base al poli(hexametilen tereftalato) y poli(butilen succinato) y se han investigado los efectos de la sustitución iónica sobre las propiedades físicas, velocidades de cristalización e hidrodegradabilidad de estos poliésteres. Además, se ha estudiado la influencia de las interacciones iónicas con nanoarcillas en la formación de nanocompuestos a base de ionómeros. Esta tesis supone un trabajo multidisciplinar que incluye síntesis, caracterización espectroscópica, evaluación de propiedades térmicas y mecánicas, estudio de la degradación hidrolítica y preparación de nanocompuestos; el proceso de síntesis de los poliésteres ha sido realizado en todos los casos mediante policondensación en estado fundido. Se han utilizado condiciones diferentes de temperatura, catalizador y tiempo para cada familia de poliésteres dependiendo de la estabilidad y de la reactividad de los comonomeros involucrados en la síntesis. Los copoliésteres sintetizados incorporaron en sus cadenas grupos iónicos sulfonados, amonio, trimetilamonio y tributil fosfonio. Los resultados de la degradación hidrolítica sugieren que la inserción de grupos sulfonados en los poliésteres, los hace más hidrofílicos permitiendo una mejor solvatación y un ataque más fácil del agua a los grupos éster. Los nanocompuestos con nanoarcillas fueron obtenidos mediante diferentes metodologías de mezclado y en algunos casos haciendo uso de compatibilizadores. Para la compatibilización se usaron el bromuro de octadeciltrimetilamonio, el dicloruro de 1,12-dodecildiamonio y un ionómero terpoliéster. Se empleó la arcilla montmorillonite tanto sin modificar como modificada con grupos alquilamonio. Se compararon los resultados obtenidos mediante los diferentes procedimientos y se evaluaron los efectos de los compatibizadores en la eficacia de mezclado y en las propiedades de los composites. La caracterización se llevó a cabo mediante resonancia magnética nuclear de $1 \mathrm{H}$ y $13 \mathrm{C}$ (NMR), espectroscopia de infrarrojo, cromatografía de exclusión molecular (GPC), calorimetría diferencial de barrido (DSC), y análisis de termogravimétrico (TGA). Los cambios en la estructura cristalina debidos a la copolimerización fueron seguidos mediante difracción de rayos X (XRD).
\end{abstract}

Enlace de acceso: http://hdl.handle.net/10803/319440 


\title{
The Molecular Toolbox: Dendrimer Decorated Biomate- rials for Musculoskeletal Regeneration
}

\author{
Autor \\ SEELBACH, RYAN \\ Directores \\ EGLIN, DAVID; LABARTA, AMILCAR; MATA, ÁLVARO \\ Universitat de Barcelona \\ Fecha de lectura: 12 junio 2015
}

\begin{abstract}
La medicina regenerativa utiliza distintos enfoques hacia procesos complejos de curación de lesiones: uno de ellos es la restauración de la función normal de tejidos mediante la combinación de biomateriales con células y fármacos. Pero si nos centramos en lo que ahora pueden hacer los biomateriales sabemos que son un material capaz de guiar tareas complejas en procesos de regeneración tisular. No obstante, la investigación en los laboratorios continua explorando este mundo inspirada por la búsqueda de soluciones para mejorar, todavía más, esta función de guía en el proceso de regeneración tisular. Hemos de ser capaces de controlar la entrega de agentes bioactivos en los microambientes que se encuentran a niveles en los que las células operan. Algunos investigadores han intentado aumentar la funcionalidad bioquímica de las estructuras de los polímeros, o "andamios" (en la literatura inglesa scaffold), mediante el control de la presentación espacial de moléculas bioactivas jugando con clústeres de secuencias de péptidos, pero sin tener un alto control a escala nanoscópica. Ahora, para el problema sobre el control de la arquitectura molecular del microambiente de un biomaterial la nanotecnología tiene una solución. Se trata de los dendrímeros, moléculas sintéticas ramificadas, simétricas, monodispersas y con forma globular. Más importante todavía, su estructura inherente mantiene una presentación estricta de los grupos terminales. Hasta este momento, nunca antes se habían mezclado covalentemente dendrímeros con biomateriales para proporcionar un control estricto de la presentación de biomoléculas en el microambiente de "andamio". Esta nueva tecnología (la de los dendrímeros) coloca a los biomateriales en el nicho para la guía de la regeneración ósea. El objetivo de estas tesis es contribuir al desarrollo de biomateriales inteligentes mediante la combinación de dendrímeros con afinidad por proteínas específicas en una plataforma de biomaterial termorreversible a base de ácido hialurónico. La meta: avanzar en el campo de la regeneración ósea.
\end{abstract}

Palabras clave: Medicina regenerativa; Regeneración (Biología); Acido hialurónico; Geles (Farmacia); Gels (Pharmacy); Dendrímero

Enlace de acceso: http://hdl.handle.net/10803/299370 